\title{
Quality Demand for Online Bookstores
}

Submitted 02/08/20, $1^{\text {st }}$ revision $29 / 08 / 20,2^{\text {nd }}$ revision $22 / 09 / 20$, accepted $20 / 10 / 20$

\section{Yi-Chan Chung ${ }^{1}$}

\section{Abstract:}

Purpose: This study distributes questionnaires to the consumers of the online bookstore $C$, and according to Importance-Performance Analysis (IPA), it recognizes the demand for quality improvement of the online bookstore $C$.

Design/Methodology/Approach: From the perspective of consumers, in this study, the customers fill out the experience to purchase products on the online bookstore C. Through Importance-Performance Analysis, this study analyzes the problems of the online bookstore $C$ for further improvement.

Findings: Based on the result of the questionnaire survey, It is suggested that the manager of online bookstore $C$ should reinforce the speed to meet the customers' needs (including products and services) and improve the webpage design of the website to allow the customers to find the products and services needed easily. It is also suggested that online bookstore $C$ should regularly learn about the consumers' needs by customer surveys to provide better services.

Practical implications: By Responsiveness, Tangible, Reliability, Empathy, and Assurance, it probes into service quality, and through Importance-Performance Analysis, it explores the difference of customers' importance and satisfaction with service quality items of the online bookstore C. The bookstore should improve these items to enhance competitiveness.

Originality/value. The research findings obtain the services that the online bookstore $C$ should improve to upgrade the service quality.

Keywords: Online bookstore, IPA, service quality.

Paper type: Research article.

ISSN: 2241-4754, H Index 10, Q3.

\footnotetext{
${ }^{1}$ Associate Professor, Department of Business Administration, Yuanpei University of Medical Technology, Taiwan, e-mail: kent4321@ms19.hinet.net;
} 


\section{Introduction}

With the vigorous development of the e-commerce market, there are various online bookstores with different operational styles. Purchasing books refers to not only the books but also service quality. Competition in the online bookstore market becomes severe, and the companies should recognize the customers' needs to attract more customers and obtain higher profits. From the perspective of consumers, in this study, the customers fill out the experience to purchase products on the online bookstore C. By questionnaire analysis, this study analyzes the online bookstore C's problems for further improvement. By Responsiveness, Tangible, Reliability, Empathy and Assurance, it probes into service quality and through Importance-Performance Analysis, it explores the difference of customers' importance and satisfaction with service quality items of the online bookstore $\mathrm{C}$. By research findings, it obtains the services which should be improved by the online bookstore $\mathrm{C}$ as the suggestion to upgrade the service quality.

\section{Literature Review}

The literature review includes two parts: a study of service quality and ImportancePerformance Analysis (IPA).

\subsection{Service quality}

Tsiotsou (2006) argued that service quality is the customers' general evaluation of the advantages, disadvantages, and ratings of the products; according to Andrew et al. (2002), service quality means the degree of satisfying the customers' needs expectation. In the service quality model constructed by Parasuraman et al. (1988), the measures of service quality are (1) tangible, (2) reliability, (3) responsiveness, (4) assurance, (5) empathy. Santos (2003) suggested that more and more researchers and companies indicate that website service is the key factor of successful e-commerce. Based on Zeithaml et al. (2002), e-service quality includes the efficiency of website function, purchase, and delivery of products and services. According to the scale proposed by Parasuraman et al. (1988), this study classifies measures of service quality of the online bookstores into Responsiveness, Tangible, Reliability, Empathy, and Assurance. The measures are based on questionnaires of Ugboma et al. (2007), Chung and Chen (2015), Parasuraman et al. (1988), Zeithaml et al. (2002), and modified according to business characteristics of the online bookstore $\mathrm{C}$.

\subsection{Importance-Performance Analysis (IPA)}

IPA was introduced by Martilla and James (1997) in 1977, who introduced a simple IPA framework that was applied to examine the performance of the automobile industry. IPA is a simple and effective analytical tool (Pike and Larkin, 2010). At present, it is commonly used in the evaluation research of service quality on customer satisfaction in the service industry as the criterion of market decision-making. IPA is 
classified into four quadrants A, B, C, and D (Zhang and Chow, 2004), as shown in Figure 1:

- Quadrant A-Zone of Concentrate Here: the company must improve it as a priority with more resources. It is the main disadvantage.

- Quadrant B - Zone of Keep Up the Good Work: the company should maintain it, and it is the main advantage.

- Quadrant C - Zone of Low Priority: it is not important for the customers, and at present, the consumers perceive low performance. It is the second disadvantage.

- Quadrant D-Zone of Possible Overkill: it is not important for the customers; however, the consumers perceive excellent performance.

Axis $\mathrm{x}$ to the right means the performance is higher. Axis $\mathrm{x}$ to the left means the performance is lower. Axis y to the top means it is more important, and axis y to the bottom means it is less important.

\section{Figure 1. IPA matrix}

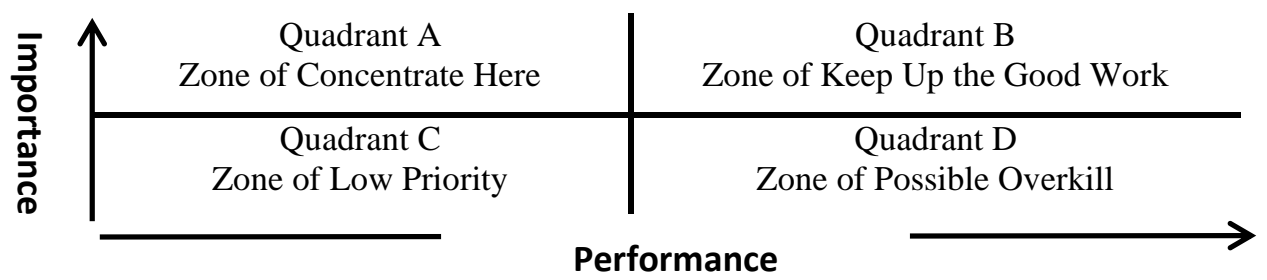

Source: Own research.

\section{Research Method}

In this study, measurement items of service quality are based on questionnaires of Ugboma et al. (2007), Chung and Chen (2015), Parasuraman et al. (1988), and Zeithaml et al. (2002) and modified according to the business characteristics of the online bookstore $\mathrm{C}$. The questionnaire is measured by Likert 5-point scale. Service quality includes the following five dimensions: (1) responsiveness; (2) tangible; (3) reliability; (4) empathy; (5) assurance; this study distributed the questionnaires from May 1 to 31,2020 . The questionnaire subjects were the customers of the online bookstore $\mathrm{C}$. This study retrieved 52 valid questionnaires.

This study adopted the IPA. The variables measured are the following: (1) responsiveness: the online bookstore immediately responds to the customers' needs (Item1); customer service personnel are willing to help and serve the customers (Item2); the website immediately responds to the customers' needs (Item3); (2) tangible: webpages of the website are clear and specific (Item4); classification of the products on the website is clear (Item5); prices on the website are specific (Item6); I 
can easily find the information needed on the website (Item7); (3) reliability: transaction system of the online bookstore is precise (Item8); the transaction is safe on the online bookstore. (Item9); transaction on the online bookstore cannot be stopped (Item10); (4) empathy: customer service personnel make efforts to solve the customers' problems (Item11); the online bookstore recognizes the customers' needs and provides proper service (Item12); the website treats the customers' profits as the priority (Item13); customer service personnel kindly solve the customers' problems (Item14); (5) assurance: customer service personnel of the website can provide responsible service (Item15); they provide various products with consistent quality with professional techniques and competence (Item16); customer service personnel respond to the customers' questions with professional knowledge (Item17); they maintain a certain degree of service quality (Item18).

\section{Research Results}

Nunnally (1978) argued that it is a high reliability when Cronbach's $\alpha$ is higher than 0.7. Cronbach's $\alpha$ of the questionnaires is higher than 0.7 , as shown in Table 1 . Thus, the reliability of this study is acceptable. The questionnaire is designed according to the literature review and theories and related literature proposed by the scholars. It meets content validity. This study adopts IPA, and the result is shown in Table 2. According to analytical result, Items in Zone of:

- $\quad$ Keep Up the Good Work are items 8, 9, 10, 14, 16, and 18;

- Items in Zone of Possible Overkill are items 11 and 15;

- Items in Zone of Low Priority are items 2, 3, 4, 5, 6, 13, and 17;

- Items in Zone of Concentrate Here are items 1, 7 and 12

Table 1. Cronbach's $\alpha$ of this study

\begin{tabular}{|c|c|c|c|}
\hline \multirow{2}{*}{ Dimensions of questionnaire } & \multirow{2}{*}{ Item } & \multicolumn{2}{|c|}{ Cronbach's $\alpha$} \\
\cline { 3 - 4 } & & Importance & Satisfaction \\
\hline Responsiveness & $1,2,3$ & 0.776 & 0.807 \\
\hline Tangible & $4,5,6,7$ & 0.828 & 0.792 \\
\hline Reliability & $8.9,10$ & 0.781 & 0.817 \\
\hline Empathy & $11,12,13,14$ & 0.836 & 0.804 \\
\hline Assurance & $15,16,17,18$ & 0.835 & 0.813 \\
\hline
\end{tabular}

Source: Own creation.

Table 2. Importance and satisfaction analysis of service quality

\begin{tabular}{|c|c|c|c|}
\hline \multicolumn{2}{|c|}{} & [Importance] & [satisfaction] \\
\hline Dimensions & Item & Average & Average \\
\hline \multirow{3}{*}{ Responsiveness } & 1 & 4.308 & 3.654 \\
\cline { 2 - 4 } & 2 & 4.154 & 3.712 \\
\cline { 2 - 4 } & 3 & 4.211 & 3.673 \\
\hline \multirow{2}{*}{ Tangible } & 4 & 4.250 & 3.750 \\
\cline { 2 - 4 } & 5 & 4.173 & 3.731 \\
\hline
\end{tabular}




\begin{tabular}{|c|c|c|c|}
\hline & & [Importance] & [satisfaction] \\
\hline \multirow[t]{3}{*}{ Dimensions } & Item & Average & Average \\
\hline & 6 & 4.212 & 3.673 \\
\hline & 7 & 4.346 & 3.788 \\
\hline \multirow{3}{*}{ Reliability } & 8 & 4.308 & 3.923 \\
\hline & 9 & 4.405 & 3.942 \\
\hline & 10 & 4.288 & 3.904 \\
\hline \multirow{4}{*}{ Empathy } & 11 & 4.250 & 3.827 \\
\hline & 12 & 4.269 & 3.731 \\
\hline & 13 & 4.212 & 3.788 \\
\hline & 14 & 4.308 & 3.808 \\
\hline \multirow{4}{*}{ Assurance } & 15 & 4.250 & 3.885 \\
\hline & 16 & 4.288 & 3.885 \\
\hline & 17 & 4.231 & 3.769 \\
\hline & 18 & 4.288 & 3.827 \\
\hline \multicolumn{2}{|c|}{ Average } & 4.264 & 3.793 \\
\hline
\end{tabular}

Source: Own creation.

\section{Conclusion}

By questionnaire survey, this study treats the customers of the online bookstore $\mathrm{C}$ as subjects. According to IPA's analytical result, items of Zone of Keep Up the Good Work are $8,9,10,14.16$, and 18 , and it is the zone of competitive advantage. The bookstore should maintain the service. Items of Zone of Possible Overkill are 11 and 15. Items of Zone of Low Priority are 2, 3,4,5,6,13, and 17. It means that they are unimportant for the customers; nevertheless, if the bookstore improves these items, they can be potential advantages. Based on the result of the questionnaire survey, items of Zone of Concentrate Here are 1, 7, and 12:

1. The online bookstore immediately responds to the customers' needs.

2. I can easily search for the information needed in the online bookstore.

3. The online bookstore recognizes the customers' needs and provides proper service.

It is suggested that the manager of online bookstore $\mathrm{C}$ should reinforce the speed to meet the customers' needs (including products and services) and improve the webpage design of the website to allow the customers to find the products and services needed easily. It is also suggested that online bookstore $\mathrm{C}$ regularly learn about the consumers' needs by customer surveys to provide better services.

\section{References:}

Andrew, J.D., Clayton, F.W., Charles, P.D. 2002. The relationship between counselor satisfaction and extrinsic job factors in state rehabilitation agencies. Rehabilitation Counseling Bulletin, 45, 223-232. 
Chung, Y.C., Chen, H.C. 2015. Study on the correlation among service quality, relationship quality and customer satisfaction- A case study of $\mathrm{H}$ hotel. International Journal of Latest Research in Science and Technology, 44(4), 1-7.

Martilla, J.A., James, J.C. 1977. Importance-Performance Analysis. Journal of Marketing, 41(1), 77-79.

Nunnally, J. 1978. Psychometric Theory (2d ed). New York: McGraw-Hill.

Parasuraman, A., Zeithaml, V.A., Berry, L.L. 1988. SERVQUAL: a multiple-item scale for measuring consumer perception of service quality. Journal of Retailing, 64(1), 1240.

Pike, S., Larkin, I. 2010. Longitudinal Evaluations of Student Satisfaction with a Postgraduate Unit Using Importance-Performance Analysis. Journal of Teaching in Travel \& Tourism, 10(3), 215-231.

Santos, J. 2003. E-service Quality: A Modal of Virtual Service Quality Dimensions. Managing Service Quality, 13(3), 233-246.

Tsiotsou, R. 2006. The Role of Perceived Product Quality and Overall Satisfaction on Purchase Intentions. International Journal of Consumer Studies, 30(2), 207-220.

Ugboma, C., Ogwude, I.C., Ugboma, O., Nnadi, K. 2007. Service Quality and Satisfaction Measurements in Nigerian Ports: An Exploration. Maritime Policy \& Management, 34(4), 331-346.

Zeithaml, V.A., Parasuraman, A., Malhotra, A. 2002. Service Quality Delivery Through Web Sites: a Critical Review of Extant Knowledge. Journal of the Academic of Marketing Science, 20(4), 362-375.

Zhang, H.Q., Chow, I. 2004. Application of importance-performance model in tour guides' performance: evidence from mainland Chinese outbound visitors in Hong Kong. Tourism Management, 25(1), 81-91. 